\title{
Unos apuntes para la historia del Instituto de Estudios Campogibraltareños
}

En abril de 1991, y como proyecto del Departamento de Cultura de la Mancomunidad de Municipios del Campo de Gibraltar, nace el Instituto de Estudios Campogibraltareños (IECG). Es su emblema una de las naves de las pinturas rupestres de la Laja Alta de Jimena de la Frontera, sobre la que se despliegan en semicírculo ocho estrellas que representan a los siete municipios de la comarca además de Gibraltar. Nace, por tanto, con vocación de establecer nexos culturales entre los ciudadanos de la zona, sin distinción de localidades o fronteras, así como de fomentar el estudio y difusión de sus valores históricos, científicos, artísticos y literarios.

Se trata de una institución eminentemente académica, sostenida en su funcionamiento administrativo por la Mancomunidad de Municipios, de la que depende como organismo autónomo. Consta de numerosos investigadores de dentro y fuera de la comarca, rondando en la actualidad en número los 200, que se dedican a difundir la cultura de la zona, recuperar sus señas de identidad y exportar su imagen más positiva a través de los medios de comunicación. Su participación en el IECG es absolutamente altruista y conforman una nutridísima nómina de expertos en todos los campos del saber al servicio del Campo de Gibraltar, al que llevan ofreciendo 20 años de colaboración desinteresada como contribución a su desarrollo y mejor conocimiento en el exterior. Se organizan en las siguientes secciones, diez en total, encabezadas por presidentes elegidos entre sus miembros: Geografía e Historia; Arqueología, Etnografía, Patrimonio y Arquitectura; Artes Plásticas y de la Imagen; Música, Teatro y Danza; Flamenco; Literatura, Filología y Ciencias de la Información; Sociología, Derecho y Ciencias Políticas y Económicas; Ciencias Exactas, Físico-Químicas y Tecnologías; Filosofía, Psicología y Ciencias de la Educación; Salud, Veterinaria, Biologia, Ecología y Ciencias de la Naturaleza.

Cada cuatro años se elige a dichos presidentes, que son quienes conjuntamente conforman la junta de consejeros. Asimismo cada cuatro años se elige al director y al vicedirector, que son asesorados por esta Junta en los asuntos académicos del Instituto. El IECG cuenta con delegaciones oficiales en Gibraltar y en Córdoba. Sus miembros académicos intervienen habitualmente, en nombre y representación del mismo, en foros de investigación nacionales e internacionales, haciendo llegar el nombre del Campo de Gibraltar a rincones insospechados. En la actualidad las relaciones son especialmente intensas con Ceuta, Gibraltar y con algunas universidades españolas. Los lazos con Gibraltar se han mantenido fluidos incluso cuando las relaciones políticas llegaron a estar seriamente afectadas y son varios, y muy activos, los miembros académicos gibraltareños que se integran en el Instituto.

Los órganos de gobierno del IECG son el presidente, que corresponde a quien ostenta la Presidencia de la Mancomunidad de Municipios del Campo de Gibraltar; el vicepresidente, coincidente con el de este cargo en el Área de Cultura de la Mancomuni- dad, y la junta rectora, en la que participan asimismo el director y el vicedirector y representantes de los grupos políticos presentes en la Junta de Comarca de la Mancomunidad. El IECG cuenta, además, con un personal técnico y administrativo, encabezado por el secretario-coordinador, miembro asimismo de la junta rectora.

Su sede, localizada provisionalmente en la Cámara de Comercio, Industria y Navegación del Campo de Gibraltar, se encuentra en el edificio que su Presidencia ocupa en el palacete eduardiano de Villa Smith, en el parque de las Acacias de Algeciras, reinaugurado en febrero de 2011 tras varios años de reformas. En febrero de 2009 fueron elegidos para ostentar la dirección del Instituto Ángel Sáez y Eduardo Briones, quienes deben desempeñar sus funciones por un periodo de cuatro años. Recientemente se ha llevado a cabo un proceso de renovación estatutaria iniciado en julio de 2007 y culminada en diciembre 2010, habiéndose actualizado algunos mecanismos que, a través de la experiencia de estos veinte años, se habian mostrado poco eficaces, si bien se mantienen todas las cuestiones esenciales del Instituto. La novedad más acusada es la ampliación del ámbito de estudio al Estrecho de Gibraltar.

Los órganos de difusión de la institución son dos: el principal y de carácter académico es la revista de estudios campogibraltareños Almoraima, nacida en 1988 , con 38 volúmenes en papel y que continúa con sus ediciones digitales ${ }^{1}$, cuyas más de 15.000 páginas se han convertido en el mejor embajador del Campo de Gibraltar en el exterior; el más reciente data de 2009 y es Diario de Avisos, un boletín digital de amplia difusión con el que da cuenta de la actualidad académica del Instituto y de los principales eventos culturales de todos los municipios de la comarca, con más de 50 números. Por otro lado, el IECG ha publicado 37 monografias en sus dos décadas de existencia, relativas a muy diferentes campos del saber. Se trata de obras de investigación o creación de autores que pueden ser o no miembros de la institución y que, si son seleccionadas por los comités de lectura correspondientes, son editados en papel ${ }^{2}$. Esta colección se encuentra prácticamente paralizada en la actualidad.

Sin embargo, la actividad de los miembros académicos no se ha visto afectada por los problemas de financiación y patrocinio actualmente existentes. Han proseguido sus estudios y reuniones, sus planes de trabajo y sus foros de debate, que se concretan en las diversas jornadas de estudio que, relativas a diferentes campos del saber, sirven de cita periódica para investigadores y aficionados. A lo largo de su dilatada historia se han celebrado once Jornadas de Historia, diez de Flora, Fauna y Ecología, tres de Arqueología y Prehistoria, dos de Literatura, una de Archivistica y otra de Etnografía. Sus actas conforman el contenido de la revista Almoraima. La sede de estas reuniones va rotando por Algeciras, Castellar de la Frontera, La Línea de la Concepción, Los Barrios, Gibraltar, Jimena de la Frontera, San Roque y Tarifa, cuyos ayuntamientos los acogen siempre de manera entusiasta.

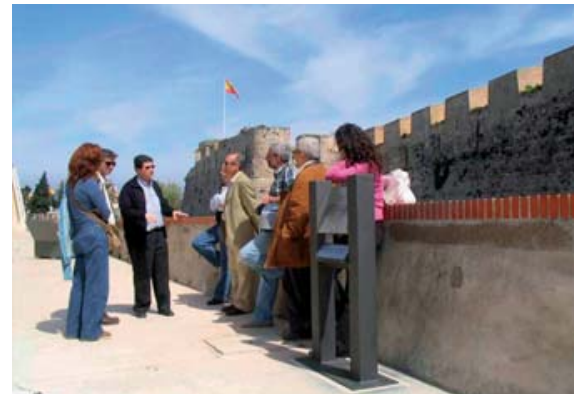

Visita a las murallas de Ceuta, actividad organizada por el IEGC. Foto: A. J. Sáez

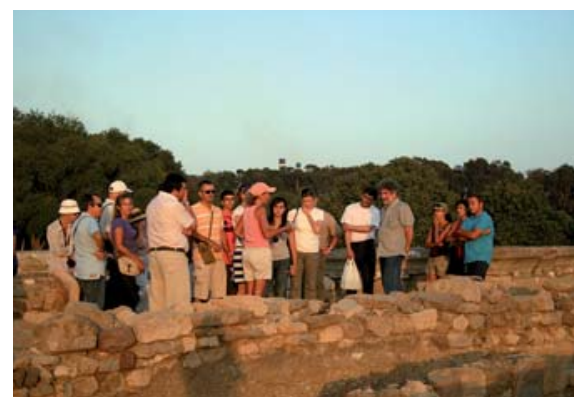

Miembros del IECG visitando el conjunto arqueológico de Carteia. Foto: A. J. Sáez

En la actualidad, y para mantener actividades académicas que sustituyan de alguna manera a todas las presentaciones de libros y revistas que han dejado de realizarse, la dirección ha organizado diferentes actos en torno a ediciones de publicaciones de miembros del Instituto de Estudios debidas a editoriales privadas. Asimismo, representantes de la institución han participado en diferentes congresos, pronunciado conferencias en instituciones culturales, intervenido en cursos universitarios, realizado visitas monumentales y publicado artículos. También han colaborado en la celebración del XIII Centenario del desembarco de Tarik; participado en la organización de las Jornadas sobre castillos y ciudades amuralladas en el Estrecho de Gibraltar con la Universidad Autónoma de Madrid y la Fundación José Luis Cano de Algeciras (Algeciras, abril de 2011); coordinado el ciclo de conferencias sobre el bicentenario del sitio de Tarifa; y nutrido el ciclo de conferencias de la Fundación José Luis Cano de Algeciras desde hace tres años, entre otras iniciativas.

Se trata, en resumen, de un interesante ejercicio de impulso a la actividad cultural de una comarca por parte de una institución académica que presenta una larga y fructifera trayectoria y que afronta con decisión las incógnitas del futuro inmediato.

\section{Ángel J. Sáez Rodríguez}

Director del IECG

\section{Notas}

'Los números publicados pueden consultarse en www.mancomunidadcg.es/iecg/numeros-revistas.aspx [consulta: 16/05/2011].

Se encuentran relacionadas en www.mancomunidadcg.es iecg/publicaciones.aspx [consulta: 16/05/2011]. 